\title{
Qualidade microbiológica de queijo mussarela em peça e fatiado
}

\section{Microbiological quality of sliced and block mozzarella cheese}

\author{
Mariana Fontanetti Marinheiro ${ }^{1 *}$; Lucas Ghedin Ghizzi²; Natacha Deboni Cereser ${ }^{3}$; \\ Helenice Gonzalez de Lima33 Cláudio Dias Timm³
}

\begin{abstract}
Resumo
O objetivo deste trabalho foi verificar o padrão microbiológico de queijo mussarela comercializado em estabelecimentos varejistas de Pelotas, Rio Grande do Sul. Foram analisadas 40 amostras de queijo mussarela, compreendendo 20 de queijo em peça e 20 de queijo fatiado, as quais foram submetidas a contagem de coliformes termotolerantes e de estafilococos coagulase positiva, e a pesquisa de Salmonella spp. e de Listeria monocytogenes. Observou-se que 12,5\% das amostras de queijo fatiado e $5 \%$ de queijo em peça estavam em desacordo com os padrões estabelecidos pela legislação brasileira. Estes resultados indicam a necessidade de maior monitoramento desses produtos e maior cuidado higiênico-sanitário durante o processamento por parte das indústrias.

Palavras-chave: Segurança de alimentos, micro-organismos indicadores, micro-organismos
\end{abstract} patogênicos

\begin{abstract}
The aim of this study was to verify the microbiological quality of mozzarella cheese sold in retail markets of Pelotas, Rio Grande do Sul, Brazil. Forty samples of mozzarella cheese were analyzed, comprising 20 samples of block cheese and 20 of sliced cheese. The cheese samples were analyzed for thermotolerant coliform counts and coagulase positive staphylococci counts, and presence of Salmonella spp and Listeria monocytogenes. The percentage of 12,5\% and 5\% of the sliced and block cheese samples analyzed, respectively, exceeded the microbiological standards accepted by Brazilian legislation. These results indicate the need for a better product monitoring and more concern with hygiene and sanitary practices during industrial process.
\end{abstract}

Key words: Food safety, indicator microorganisms, pathogenic microorganisms

\footnotetext{
1 Médica Veterinária, Especialista em Inspeção de Leite e Derivados pelo Programa de Residência Multiprofissional em Saúde, área Medicina Veterinária, Universidade Federal de Pelotas, UFPel, Pelotas, RS. E-mail: mariana_mfm@hotmail.com

2 Discente do Curso de Mestrado do Programa de Pós Graduação em Zootecnia, Universidade Tecnológica Federal do Paraná, UTFPR, Dois Vizinhos, PR. E-mail: lucas.ghizzi@gmail.com

3 Profs., UFPel, Pelotas, RS. E-mail: natachacereser@yahoo.com.br; helenicegonzalez@hotmail.com; claudiotimm@hotmail. com

* Autor para correspondência
} 
Segundo o Ministério da Agricultura, Pecuária e Abastecimento (MAPA), define-se como queijo o produto obtido da separação parcial do soro do leite, coagulado por ação física, enzimática, bacteriana, ácidos orgânicos isolados ou combinados, todos aptos ao consumo, com ou sem agregação de substâncias alimentícias e/ou especiarias e/ou condimentos, aditivos especificamente indicados, substâncias aromatizantes e matérias corantes (BRASIL, 1996).

O queijo mussarela é amplamente utilizado na culinária, no preparo de pratos quentes e sanduíches, por conta de suas propriedades de fatiamento e facilidade de derretimento (COELHO et al., 2012). É o tipo de queijo com a maior produção no país $(28,4 \%)$, seguido pelo prato $(19,9 \%)$ e o requeijão culinário (18,7\%), atingindo cerca de 200.000 toneladas no ano de 2009 (LIMA FILHO; POMBO, 2010).

O método de fabricação do queijo pode envolver vários processos, tais como a pasteurização do leite, coagulação, corte do coágulo, dessoragem, filagem, enformagem, salga, maturação e embalagem. A grande manipulação do produto, que entra em contato com diferentes equipamentos e superfícies, aumenta o risco de contaminação microbiológica (PINTO et al., 2009).

O queijo é um alimento rico em nutrientes, o que favorece a proliferação de micro-organismos que podem levar a alterações nas características organolépticas do produto e ou causar toxiinfecções alimentares nos consumidores. Os coliformes, por exemplo, são considerados microorganismos indicadores, ou seja, quando detectados em populações elevadas no alimento indicam higiene inadequada no processamento e, no caso de coliformes termotolerantes, provável presença de micro-organismos patogênicos (PIETROWSKI et al., 2008). Além disso, o sabor do queijo é alterado, devido à produção de compostos decorrentes do metabolismo bacteriano, como o ácido acético (SANTOS-KOELLN; MATTANA; HERMES, 2009).
Staphylococcus aureus, Salmonella enterica e Listeria monocytogenes são micro-organismos causadores de doenças transmitidas por alimentos (DTA), os quais podem ocasionalmente ser encontrados em queijos. As enfermidades que essas bactérias podem causar nos consumidores vão desde leves distúrbios gastrointestinais, como diarreia e vômitos, até síndromes graves, aborto e morte (PINTO et al., 2009.)

A Agência Nacional de Vigilância Sanitária - ANVISA (BRASIL, 2001) estabelece padrões microbiológicos para diversos alimentos. Para os queijos de média umidade, no qual está incluída a mussarela, é exigida ausência de Salmonella e L. monocytogenes em $25 \mathrm{~g}$ do alimento e são estabelecidos os valores máximos de $10^{3} \mathrm{UFC} / \mathrm{g}$ para estafilococos coagulase positiva e $10^{3} \mathrm{UFC} / \mathrm{g}$ para coliformes a $45^{\circ} \mathrm{C}$ ou termotolerantes.

O objetivo deste trabalho foi verificar o padrão microbiológico do queijo mussarela fatiado e em peça comercializado na região sul do Rio Grande do Sul, de acordo com os padrões estabelecidos pela ANVISA.

Um total de 40 amostras de queijo mussarela foi analisado, sendo 20 amostras de queijo em peça e 20 de queijo fatiado dentro do laticínio. Os queijos eram produzidos por indústrias sob inspeção federal ou estadual, comercializados em redes varejistas da cidade de Pelotas, RS. Foram coletadas amostras de queijo com a data de fabricação mais recente possível, visando minimizar os efeitos que uma conservação inadequada no local de comércio pudesse gerar. As amostras, mantidas em suas embalagens originais de venda, foram acondicionadas em caixas isotérmicas com gelo e imediatamente transportadas ao laboratório para realização das análises.

Foram realizadas contagens de coliformes termotolerantes e de estafilococos coagulase positiva e pesquisas de Salmonella e de L. monocytogenes, conforme os Métodos Analíticos Oficiais para Análises Microbiológicas para Controle de Produtos 
de Origem Animal recomendados pelo Ministério da Agricultura, Pecuária e Abastecimento (BRASIL, 2003).

Para a análise presuntiva de coliformes termotolerantes, pesou-se assepticamente 25 gramas de cada amostra, que foram colocados em saco plástico estéril com $225 \mathrm{~mL}$ de solução salina peptonada $0,1 \%$ (Himedia, Mumbai, Índia) e homogeneizados em stomacher (Logen Scientific, São Paulo, Brasil), obtendo-se assim a diluição $10^{-1}$. A partir desta, foram feitas diluições decimais, adicionando $1 \mathrm{~mL}$ de cada diluição em 9 $\mathrm{mL}$ de solução salina peptonada $0,1 \%$ (Himedia), sucessivamente. Um $\mathrm{mL}$ de cada diluição foi pipetado, em triplicata, para tubo de ensaio com 10 $\mathrm{mL}$ de caldo Lauril Sulfato de Sódio (Isofar, Rio de Janeiro, Brasil) contendo tubo de Durhan invertido, os quais foram incubados a $36 \pm 1^{\circ} \mathrm{C}$ por 48 horas. A presença de coliformes é indicada pela formação de gás no tubo de Durhan. Para prova confirmativa de coliformes termotolerantes, foi feita inoculação, a partir dos tubos positivos na etapa anterior, em caldo Escherichia coli (Acumedia, Michigan, USA) e incubação a $45 \pm 0,2^{\circ} \mathrm{C}$ por 48 horas. $\mathrm{O}$ resultado foi obtido com o uso de tabela para número mais provável (NMP).

Para a contagem de estafilococos coagulase positiva, diluições seriadas de base 10 foram semeadas, em duplicata, em ágar Baird-Parker (Himedia) e incubadas a $36 \pm 1^{\circ} \mathrm{C}$ por 48 horas. Cinco colônias típicas e cinco atípicas de cada placa foram inoculadas em Caldo Infusão de Cérebro e Coração (Himedia) e incubadas a $36 \pm 1^{\circ} \mathrm{C}$ por 24 horas para realização da prova da coagulase, que consistiu na mistura de $0,3 \mathrm{~mL}$ da suspensão de cada cultura em caldo infusão de cérebro e coração (Himedia) com 0,3 mL de plasma de coelho (Laborclin, Pinhais, Brasil) e incubação a $36 \pm 1^{\circ} \mathrm{C}$ por 6 horas para observação de coagulação. Calculou-se a proporção de colônias coagulase positivas em relação à contagem de colônias típicas e atípicas na placa e o resultado final da contagem de cada placa foi obtido pela soma do número de colônias coagulase positivas. Após, foi calculada a média das duplicatas e realizada a correção da diluição utilizada para a contagem.

Para análise de Salmonella, pesou-se $25 \mathrm{~g}$ da amostra, que foram adicionados a $225 \mathrm{~mL}$ de Água Peptonada Tamponada a 1\% (Himedia) e incubados a $36 \pm 1^{\circ} \mathrm{C}$ por 16 a 20 horas para pré-enriquecimento. $\mathrm{O}$ enriquecimento seletivo foi realizado com em caldo Rappaport Vassiliadis (Acumedia) e em caldo Tetrationato (Acumedia) a $41 \pm 0,5^{\circ} \mathrm{C}$ por 24 a 30 horas. Os meios seletivos-diferenciais utilizados foram ágar Verde brilhante Vermelho de fenol Lactose Sacarose (BPLS) (Acumedia) e ágar Xilose Lisina Desoxicolato (XLD) (Himedia) incubados a $36 \pm 1^{\circ} \mathrm{C}$ por 18 a 24 horas. Das placas que apresentaram crescimento característico de Salmonella, três colônias foram utilizadas para realização de testes bioquímicos e sorologia, conforme recomendações de BRASIL (2003).

Para pesquisa de L. monocytogenes, $25 \mathrm{~g}$ da amostra foram homogeneizados em $225 \mathrm{~mL}$ de caldo de enriquecimento para Listeria (UVM) (Acumedia), que foi incubado a $30 \pm 1^{\circ} \mathrm{C}$ por 24 horas. Em seguida, 0,1 mL da cultura foi inoculado em 10 $\mathrm{mL}$ de caldo Fraser (Acumedia) e incubado a $30 \pm 1^{\circ} \mathrm{C}$ por 24 a 48 horas. Os meios seletivo-diferenciais utilizados foram ágar Palcan (Acumedia) e ágar Oxford (Acumedia), incubados a $30 \pm 1^{\circ} \mathrm{C}$ por 24 a 48 horas. Das placas que apresentaram crescimento característico de Listeria, três colônias foram utilizadas para a identificação da espécie, conforme recomendações de BRASIL (2003).

Os resultados das análises estão apresentados na Tabela 1. Cinco amostras de queijo (12,5 $\%$ apresentaram contagem de coliformes termotolerantes maior ou igual a $1100 \mathrm{NMP} / \mathrm{g}$, em desacordo com o estabelecido pela legislação vigente). A presença de coliformes nos alimentos indica que pode ter ocorrido contaminação durante o processo de fabricação ou após o processamento (SANTOS-KOELLN; MATTANA; HERMES, 2009). Em estudos semelhantes realizados em Goiás 
(QUINTANA; CARNEIRO, 2007; RODRIGUES et al., 2011) e Paraná (PIETROWSKI et al., 2008; SANTOS-KOELLN; MATTANA; HERMES, 2009), foi relatado que todas as amostras analisadas encontravam-se dentro dos limites estabelecidos pela legislação, o que também seria de se esperar com as amostras analisadas no presente trabalho, já que os queijos foram produzidos em indústrias com inspeção federal ou estadual. É importante ressaltar que somente para o padrão coliformes termotolerantes foi encontrado amostras de queijo em peça em desacordo com a legislação vigente. $\mathrm{Na}$ avaliação dos demais padrões microbiológicos, somente amostras de queijo fatiado estavam fora das especificações.

Tabela 1. Número de amostras de queijo mussarela em peça e fatiado com resultados em desacordo com a RDC n ${ }^{\circ} 12$ de 02 de janeiro de 2001 da Agência Nacional de Vigilância Sanitária - ANVISA (BRASIL, 2001).

\begin{tabular}{cccccc}
\hline $\begin{array}{c}\text { Forma de } \\
\text { comercialização }\end{array}$ & $\begin{array}{c}\text { Coliformes } \\
\text { termotolerantes } \\
(\%)\end{array}$ & $\begin{array}{c}\text { Estafilococos } \\
\text { coagulase positiva } \\
(\%)\end{array}$ & $\begin{array}{c}\text { Salmonella } \\
\text { spp.(\%) }\end{array}$ & $\begin{array}{c}\text { Listeria } \\
\text { monocytogenes }(\%)\end{array}$ & $\begin{array}{c}\text { Total de } \\
\text { amostras }\end{array}$ \\
\hline Peça & $2(10)$ & 0 & 0 & 0 & 20 \\
Fatiado & $3(15)$ & $4(20)$ & $1(5)$ & $1(5)$ & 20 \\
Total & $5(12,5)$ & $4(10)$ & $1(2,5)$ & $1(2,5)$ & 40 \\
\hline
\end{tabular}

Fonte: Elaboração dos autores.

Quatro amostras de queijo fatiado (20,0\%) apresentaram contagens de estafilococos coagulase positiva maiores que o limite de $10^{3}$ $\mathrm{UFC} / \mathrm{g}$ estabelecido pela legislação. Pietrowski et al. (2008) também obtiveram três amostras $(18,75 \%)$ com valores acima de $10^{3} \mathrm{UFC} / \mathrm{g}$ ao analisarem queijo fatiado, o que indica que o risco de contaminação pode aumentar muito com esta etapa do processamento. No queijo em peça, todas as amostras analisadas estavam dentro do padrão. Quintana e Carneiro (2007) e Santos-Koelln, Mattana e Hermes (2009) também encontraram $100 \%$ de amostras de queijo mussarela em peça dentro dos padrões estabelecidos pela legislação. Por outro lado, Rodrigues et al. (2011) observaram quatro das 11 amostras de mussarela em peça analisadas com contagens acima do padrão. A ocorrência de amostras positivas para estafilococos coagulase positiva pressupõe que o tratamento térmico do leite para a fabricação do queijo tenha sido ineficiente ou que tenha ocorrido contaminação após o tratamento, devido à manipulação ou contato com superfícies não sanitizadas adequadamente (KOMATSU et al., 2010).
A presença de Salmonella foi identificada em uma amostra de mussarela fatiada. De acordo com a legislação, Salmonella e L. monocytogenes devem estar ausentes em $25 \mathrm{~g}$ de amostra, devido à sua capacidade de causar doença nos seres humanos. Outros estudos envolvendo mussarela verificaram a ausência desse micro-organismo nas amostras analisadas (SANTOS-KOELLN; MATTANA; HERMES, 2009; RODRIGUES et al., 2011), o que seria o esperado considerando que esses produtos haviam sido submetidos a inspeção prévia. Pietrowsky et al. (2008) também observaram a presença desse micro-organismo em uma $(6,25 \%)$ das 16 amostras de mussarela fatiada analisadas, o que evidencia o aumento do risco de contaminação em produtos fatiados.

L. monocytogenes foi isolada em uma das amostras de queijo fatiado. Ratti (2006), ao avaliar 30 amostras de mussarela fatiada, também observou a presença de L. monocytogenes em uma das amostras analisadas (3,3\%). Em um estudo retrospectivo, Silva et al. (2011) encontraram que, de 3428 amostras de diversos tipos de queijo, 111 
(3,24\%) foram positivas para L. monocytogenes. É importante ressaltar que nessa revisão, grande parte dos estudos envolveu a análise de queijo Minas e produtos artesanais, diferentemente do presente trabalho, em que foram analisadas amostras de queijo mussarela produzidas por indústrias com inspeção estadual ou federal, onde se espera que exista um maior cuidado com as práticas higiênicosanitárias. A presença de L. monocytogenes é menor em estudos envolvendo produtos industrializados e inspecionados. A listeriose, apesar de rara, é considerada de grande importância para a saúde pública, devido à seriedade dos agravos que pode causar aos seres humanos. Na Europa, ela é a segunda maior causa de óbitos resultantes das Doenças Transmitidas por Alimentares (DTAs), ficando atrás somente da salmonelose (ALLERBERGER; WAGNER, 2010).

No presente estudo, do total de 40 amostras de mussarela, sete foram consideradas em desacordo com os padrões estabelecidos pela RDC n ${ }^{\circ} 12$ de 02 de janeiro de 2001 da ANVISA (BRASIL, 2001), sendo cinco de queijo fatiado e duas de queijo em peça. É importante ressaltar que uma das amostras de queijo fatiado apresentou desacordo em três padrões, coliformes termotolerantes, Salmonella e Listeria monocytogenes. A maioria das amostras fora do padrão correspondia ao produto fatiado, provavelmente por esses produtos passarem por uma etapa a mais (fatiamento) antes de serem embalados, o que faz com que entrem em contato com novas superfícies, equipamentos e manipuladores. Além disso, ao se fracionar qualquer produto sólido, aumenta-se sua superfície exposta, o que pode aumentar os riscos de contaminação. Entre os poucos artigos encontrados na literatura sobre a avaliação de queijo mussarela fatiado, Ratti (2006) e Rall et al. (2009) encontraram alta frequência de amostras fora do padrão.

Através dos resultados obtidos, observou-se que apesar do controle sanitário realizado pelos órgãos de fiscalização, ainda são encontrados no comércio produtos acabados fora dos padrões de qualidade, especialmente os fatiados. Ressalta-se a importância de um maior cuidado na elaboração e aplicação dos programas de autocontrole da indústria, em especial no que se relaciona à higiene dos manipuladores e à limpeza e desinfecção de equipamentos e superfícies que entram em contato com o alimento, e maior rigor na fiscalização pelos órgãos de inspeção oficial, com intuito de reduzir a comercialização de produtos contaminados.

\section{Referências}

ALLERBERGER, F.; WAGNER, M. Listeriosis: a resurgent foodborne infection. European Journal of Clinical Microbiology and Infectious Diseases, Berlin, v. 16, n. 1, p. 16-23, 2010.

BRASIL. Agência Nacional de Vigilância Sanitária - Anvisa. Regulamento Técnico sobre Padrões Microbiológicos para Alimentos. Resolução-RDC nº12, de 02 de janeiro de 2001, Diário Oficial [da] União, Brasília, nº 7, 10 jan. 2001. Seção 1, p. 45-53.

Ministério da Agricultura, Pecuária e Abastecimento. Aprova os regulamentos técnicos de Identidade e Qualidade dos produtos lácteos. Portaria ${ }^{\circ}$ 146 de 07 de março de 1996. Diário Oficial [da] União, Brasília, 11 mar. 1996. Seção 1, p. 39-77.

Ministério da Agricultura, Pecuária e Abastecimento, Secretaria de Defesa Agropecuária. Métodos Analíticos Oficiais para Análises Microbiológicas para Controle de Produtos de Origem Animal e Água. Instrução Normativa $\mathrm{n}^{\circ} 62$, de 26/08/2003. Diário Oficial [da] União, Brasília, 18 set. 2003. Seção 1, p. 14-51.

COELHO, K. O.; MESQUITA, A. J.; MACHADO, P. F.; OLIVEIRA, A. N.; SOUZA, C. M.; MEYER, P. M. Níveis de células somáticas sobre a proteólise do queijo Mussarela. Revista Brasileira de Saúde e Produção Animal, Salvador, v. 13, n. 3, p. 682-693, 2012.

KOMATSU, R. S.; RODRIGUES, M. A. M.; LORENO, W. B. N.; SANTOS, K. A. Ocorrência de Staphylococcus coagulase positiva em queijo minas frescal produzido em Uberlândia-MG. Bioscience Journal, Uberlândia, v. 26, n. 2, p. 316-321, 2010.

LIMA FILHO, R. R.; POMBO, G. Aumenta o consumo de queijo no Brasil. Bebedouro: Carta Leite, 2010. 105 p. 
PIETROWSKI, G. A. M.; RANTHUM, M.; CROZETA, T.; JONGE, V. Avaliação da qualidade microbiológica de queijo tipo Mussarela comercializado na cidade de Ponta Grossa, Paraná. Revista Brasileira de Tecnologia Agroindustrial, Ponta Grossa, v. 2, n. 2, p. 25-31, 2008.

PINTO, M. S.; FERREIRA, C. L. F.; MARTINS, J. M.; TEODORO, V. A. M.; PIRES, A. C. S.; FONTES, L. B. A.; VARGAS, P. I. R. Segurança alimentar do queijo minas artesanal do Serro, Minas Gerais, em função da adoção de boas práticas de fabricação. Revista Pesquisa Agropecuária Tropical, Goiânia, v. 39, n. 4, p. 342-347, 2009.

QUINTANA, R. C.; CARNEIRO, L. C. Avaliação das condições higiênico-sanitárias dos queijos minas frescal e mussarela produzidos na cidade de Morrinhos - GO. Revista Brasileira de Saúde e Produção Animal, Salvador, v. 8, n. 3, p. 205-211, 2007.

RALL, R.; DORICO, J. A.; RALL, V. L. M.; ALQUATI, L. H. Queijos e embutidos pré fatiados: Um perigo aos consumidores? In: ETIC -ENCONTRO DE INICIAÇÃO CIENTÍFICA, 5., 2009, Presidente Prudente. Presidente Prudente: Toledo, 2009. Disponível em: <http:// intertemas.unitoledo.br/revista/index.php/ETIC/article/ view/2211/2371>. Acesso em: 27 out. 2012.
RATTI, R. P. Listeria monocytogenes em alimentos fatiados e equipamentos: ocorrência, formação de biofilme e controle. 2006. Dissertação (Mestrado em Biociências Aplicadas à Farmácia) - Universidade de São Paulo, Ribeirão Preto.

RODRIGUES, J.; FIDELIS DE FARIAS, H. L.; BARBOSA, B. F. F.; GARCIA, T. A.; ISSY, P. N.; ARMONDES, M. P. O. Levantamento das características físico-químicas e microbiológicas de queijo minas frescal e mussarela produzidos no entorno de GoiâniaGO. Revista da Universidade Vale do Rio Verde, Três Corações, v. 9, n. 1, p. 30-34, 2011.

SANTOS-KOELL, F. T.; MATTANA, A.; HERMES, E. Avaliação microbiológica do queijo tipo mussarela e queijo colonial comercializado na região oeste do Paraná. Revista Brasileira de Tecnologia Agroindustrial, Ponta Grossa, v. 3, n. 2, p. 66-74, 2009.

SILVA, A. S.; ARAGON, C. C.; SANTANA, E. H. W.; DESTRO, M. T.; COSTA, M. R.; ALEGRO, L. C. A. Listeria monocytogenes em leite e produtos lácteos no Brasil: Uma revisão. UNOPAR Cientifica - Ciências Biológicas e da Saúde, Londrina, v. 13, n. 1, p. 59-67, 2011. 